\title{
Intrathoracic Fracture-dislocation of the Humeral Head: A Case Report and Review of the Literature
}

\author{
Ruifeng Yang1, Shuhua Lan ${ }^{1}$, Quanzhou Wu${ }^{1}$, Fang Ye ${ }^{1}$, Jifei Ye ${ }^{1}$, Shuming Huang ${ }^{1}$, Panpan Xie ${ }^{1}$, Hailin Xing ${ }^{1}$ and \\ Chong Wang1,*
}

1 Department of Orthopaedics, Lishui Central Hospital, Lishui, Zhejiang, China

* Corresponding author: Chong Wang, Department of Orthopaedics, Lishui Central Hospital, NO.289 Kuocang Road, Liandu District, Lishui, Zhejiang, 323000, China. Tel: +8613567615800; Email: 252000966@qq.com

Received 2021 June 14; Revised 2021 August 01; Accepted 2021 August 03

\begin{abstract}
Introduction: Intrathoracic displacement of a humeral head fracture is extremely rare. Only slightly more than 30 cases have been reported in this regard. Since few cases have been reported, there is no consensus on how to treat this injury. The etiology, injury mechanism, related lesions, and treatment of the injury are diverse.

Case Presentation: A 73-year-old female presented with multiple fractures of the left ribs, bilateral lung contusions, extensive emphysema of the anterior and posterior chest wall, massive left hemopneumothorax, fracture-dislocation of the proximal humerus, and intrathoracic displacement of the humeral head. The patient was sent to the operating room for emergency thoracotomy surgery. The head of the humerus was confirmed to be completely removed from the thoracic cavity during the operation. After discussion with the orthopedic surgeon, the humeral head was discarded considering avascular necrosis; moreover, open reduction and internal fixation were not performed. The orthopedic surgery team performed reverse shoulder arthroplasty three weeks later. During follow-up, the patient's shoulder was free from pain, and its range of movement included $110^{\circ}$ flexion, $70^{\circ}$ abduction, $35^{\circ}$ external rotation, and $50^{\circ}$ internal rotation.

Conclusion: Intrathoracic displacement of the humeral head due to proximal humeral fracture is a very rare and serious trauma that requires multidisciplinary treatment. Considering the extremely high risk of humeral head necrosis, actively removing broken bone fragments of the humeral head in the early stage is recommended, and we advocate for shoulder arthroplasty for elderly patients. Detailed preoperative evaluations and individualized operation plans should be made to achieve the best effect.
\end{abstract}

Keywords: Arthroplasty, Humeral fractures, Intrathoracic dislocation, High-energy trauma, Thoracic injuries

\section{Introduction}

Intrathoracic fracture-humeral head dislocation has been rarely reported and requires a combination of high-energy trauma and specific mechanisms. Considering the enumeration of the mechanism of injury, most of which are high-energy injuries. This study investigates a case report of intrathoracic fracture-dislocation of the humeral head. The reviews included falls from height $(n=18)(1-18)$, motor vehicle accidents $(n=7)(19-25)$, knockdown by motor vehicles $(n=2)(26,27)$, falling from standing height $(n=2)(28$, $29)$, and falling from a bicycle $(n=1)(30)$.

This study aimed to review the published cases to examine the etiology, mechanism, related injuries, and treatment of this rare injury. This study described a patient who suffered from an intrathoracic fracture-dislocation of the humeral head after a high-energy traffic accident.

\section{Case presentation}

A 73-year-old female presented to the emergency department after a high-speed motor vehicle accident with the chief complaint of left chest pain accompanied by dyskinesia with dyspnea. The patient's left shoulder was injured with local tenderness and loss of function. She denied loss of consciousness. The patient was evaluated and treated according to the concepts of advanced trauma life support (ATLS) and damage control surgery. The Glasgow coma scale was 15 . Admission vital signs included body temperature of $36.7^{\circ} \mathrm{C}$, blood pressure of $104 / 68 \mathrm{mmHg}$, pulse 87 of times/min, respiratory rate of 25 times/min, and blood oxygen saturation of $90 \%$. Physical examination of the left upper limb revealed left shoulder swelling, deformity, severe instability, dyskinesia, ecchymosis, strong pulsation of the radial artery, and no obvious hypoesthesia. There was obvious subcutaneous emphysema in the left chest, tenderness in the front of the left ribs, and decreased respiratory movement and respiratory sounds. Radiography and computed tomography (CT) showed multiple fractures of the left ribs, bilateral lung contusions, extensive emphysema of the anterior and posterior chest wall, massive left hemopneumothorax, fracture-dislocation of the proximal humerus, and intrathoracic displacement of the humeral head (Figures 1-3).

After stabilizing the patient with the ATLS regimen, the patient was sent to the operating room for emergency thoracotomy surgery. A thoracic drainage tube was inserted and fixed in the sixth intercostal space of the left axillary midline after complete hemostasis. The third and fourth ribs were 


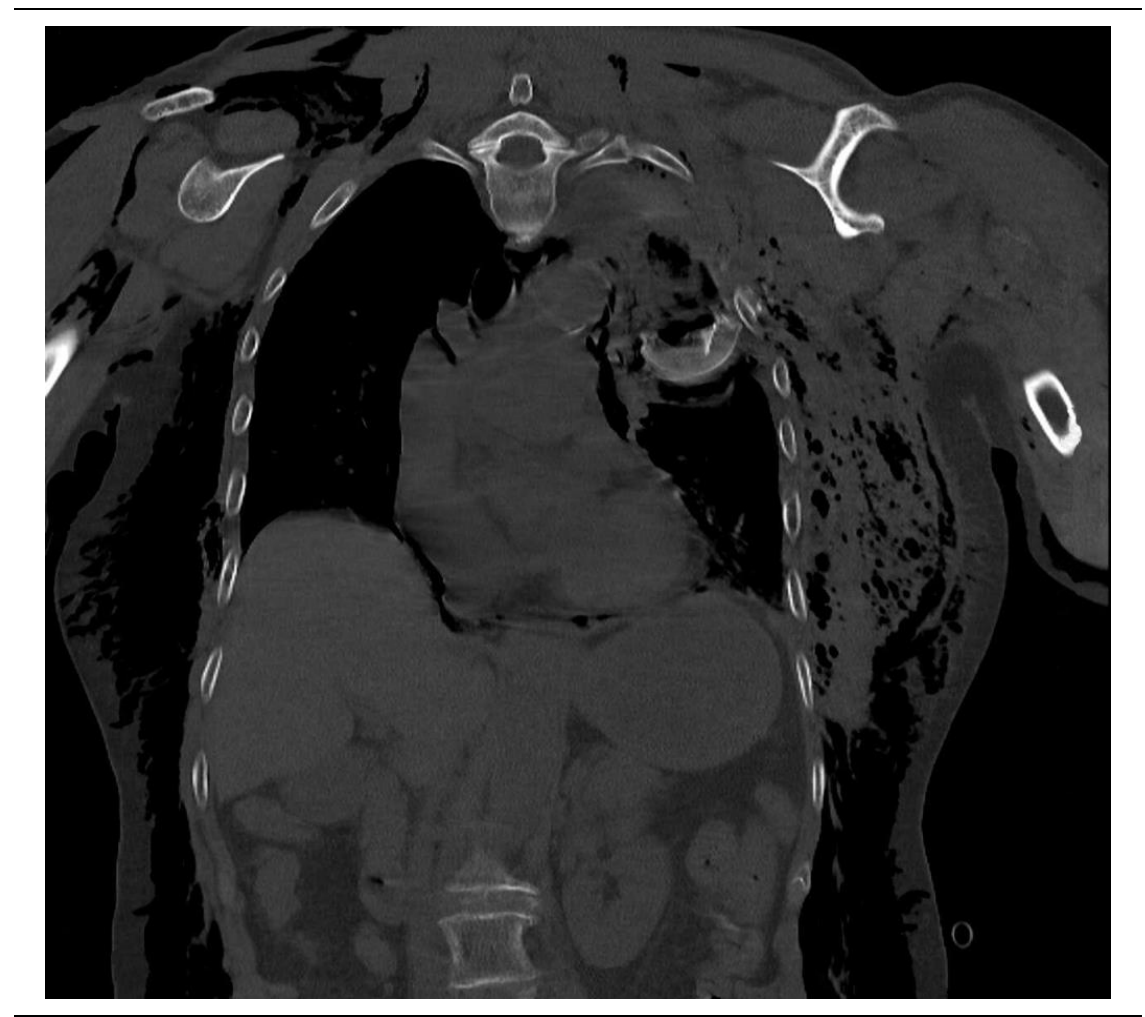

Figure 1. CT scan showing the intrathoracic localization of the humeral head.

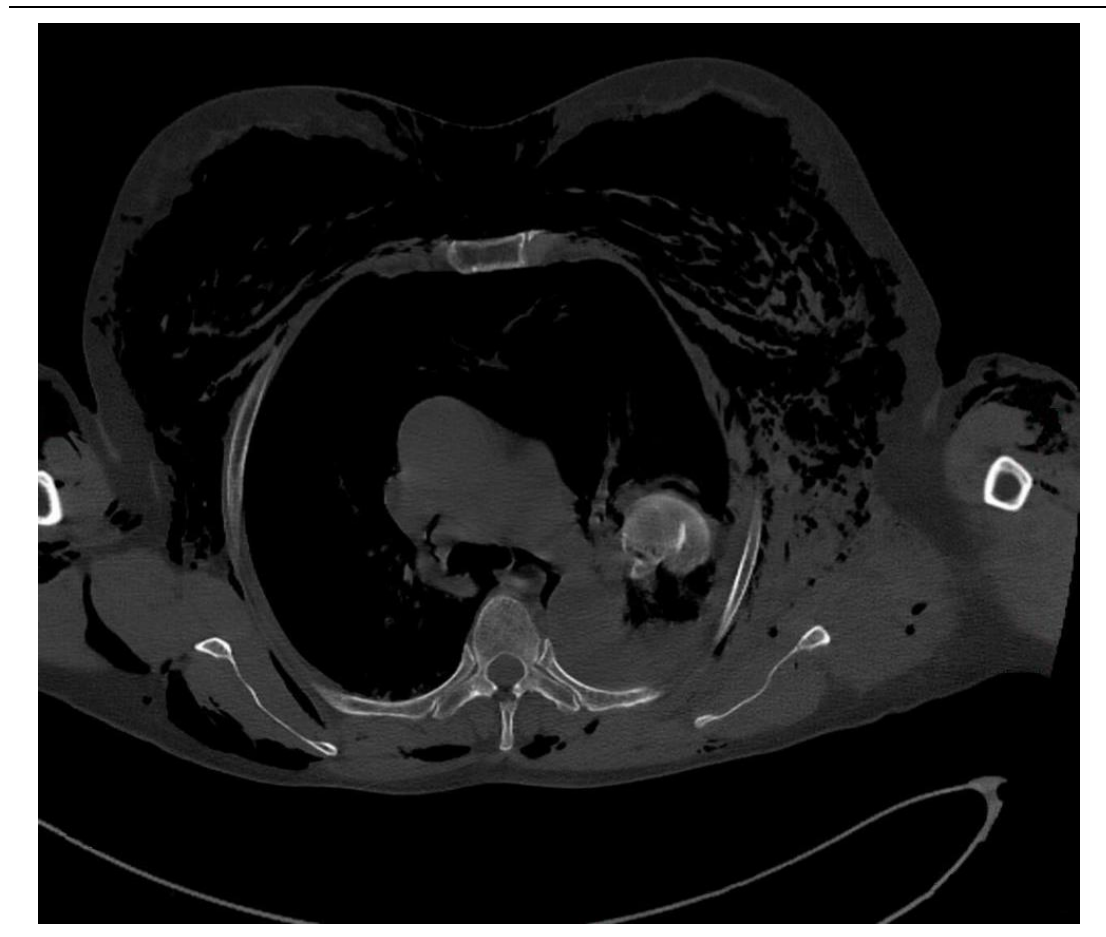

Figure 2. CT scan showing the intrathoracic localization of the humeral head.

fixed with a rib embracing fixator. The operation was successful, and the patient was transfused with 370 $\mathrm{mL}$ plasma and 5 units of packed red cells. Subsequently, the patient was further treated in the intensive care unit.

The head of the humerus was confirmed to be completely removed from the thoracic cavity during the operation (Figure 4). After discussion with the orthopedic surgeon, the humeral head was discarded considering avascular necrosis; moreover, open reduction and internal fixation were not performed. Electromyography (EMG) showed normal axillary 


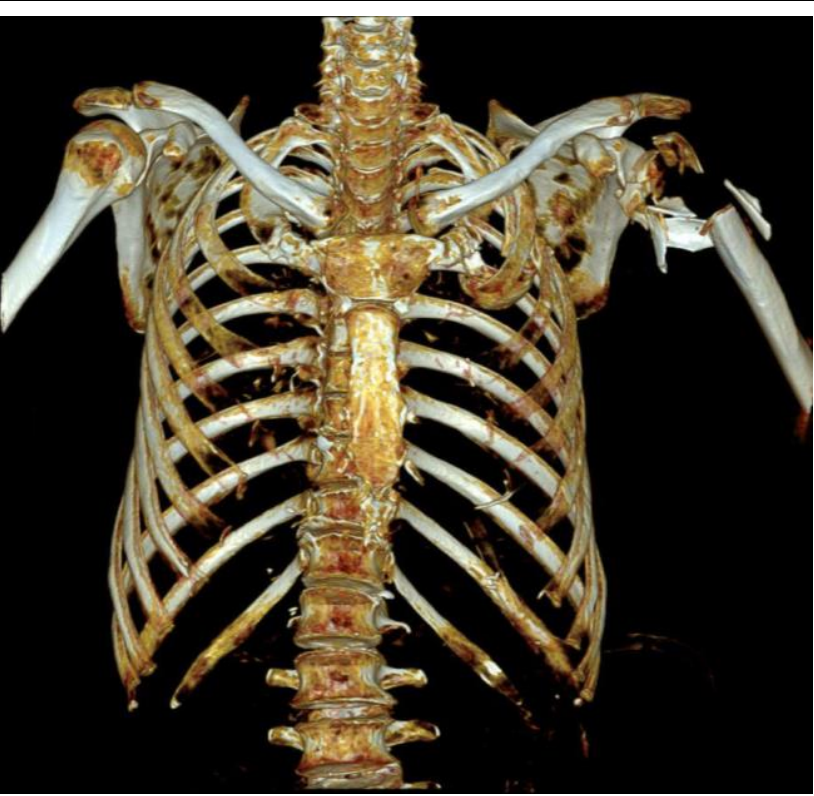

Figure 3. Three-dimensional reconstruction CT showing the intrathoracic displacement of humeral head and ribs fracture.

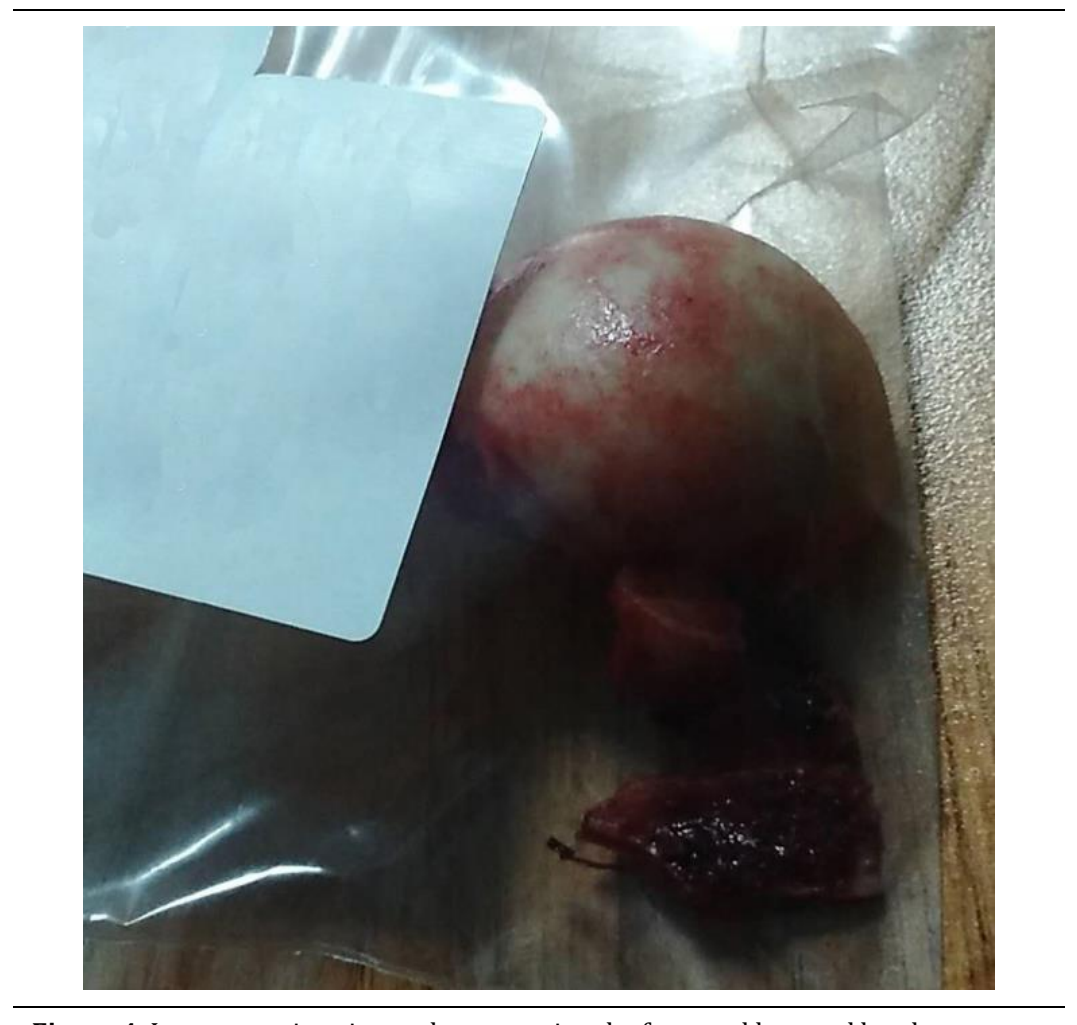

Figure 4. Intra-operative picture demonstrating the fractured humeral head.

nerve three weeks later. Therefore, the orthopedic surgery team performed reverse shoulder arthroplasty (Figure 5). The patient was being well after reoperation.

Postoperative rehabilitation protocol: $0 \sim 6 \mathrm{w}$ after surgery: Patients were educated to make them understand the significance of postoperative rehabilitation. It includes boxing pump, assisted flexion and extension, pendulum movement, active flexion and extension of elbow and wrist, as well as shoulder abduction pillow and shrug. Oral Celebrex was given to patients within three weeks after surgery to reduce pain and prevent ectopic ossification. $7 \sim 12 \mathrm{w}$ after operation: Assisted external rotation, deltoid isometric contraction, table cleaning exercises, and wall climbing exercises. At the 


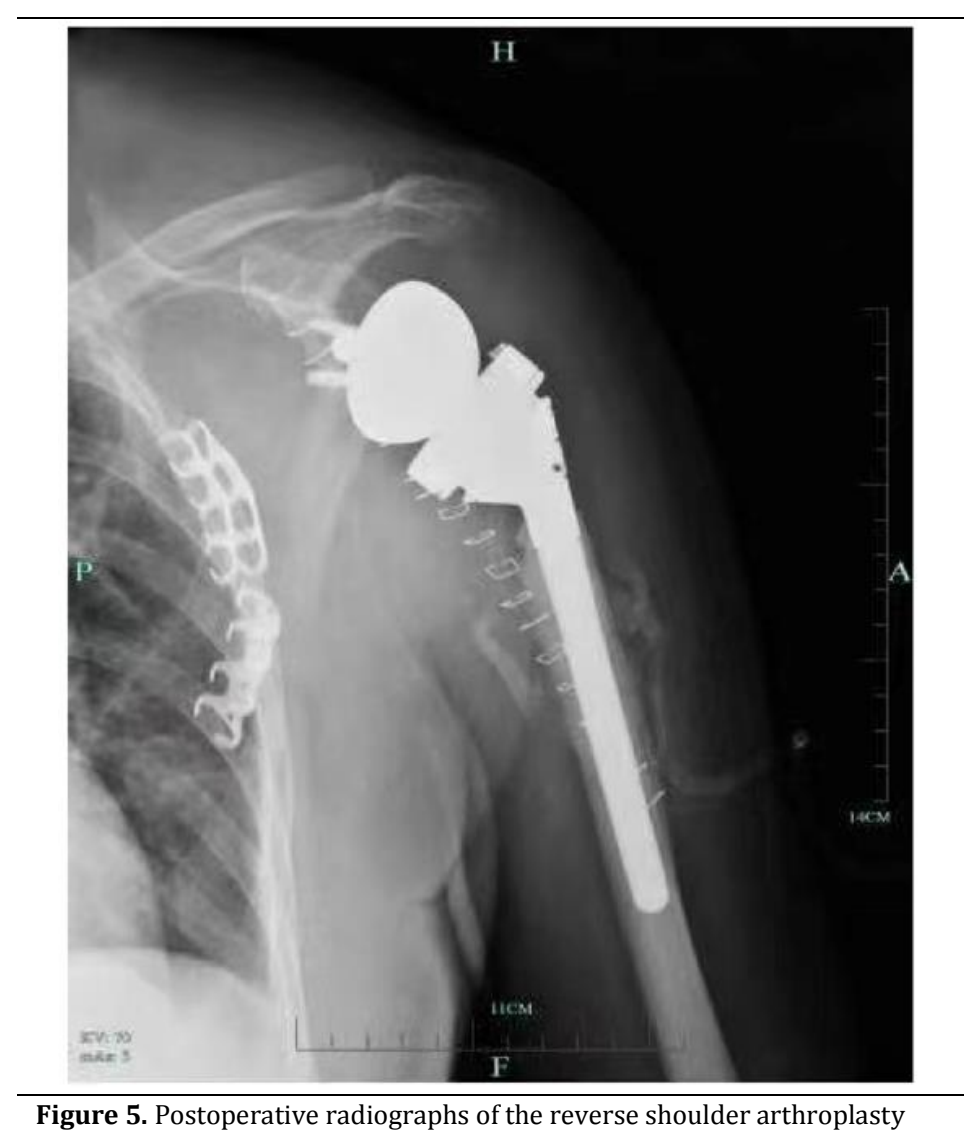

final follow-up, the patient's shoulder was free from pain, and its range of movement (ROM) included $110^{\circ}$ flexion, $70^{\circ}$ abduction, $35^{\circ}$ external rotation, and $50^{\circ}$ internal rotation.

\section{Discussion}

Humeral head fracture-dislocation and penetration into the chest are injuries that have been rarely reported in the literature. To date, only 30 cases have been recorded in the literature. No treatment guidelines are currently available, and there is high variability in the management of these patients, even diametrically opposed treatment options. Treatment has to be individualized for each patient.

The literature on this subject is limited; accordingly, the mechanism of the injury has not been elucidated. Hardcastle et al. (31) believed that the occurrence of injury can be divided into two stages. First, a drop in forced abduction with external rotation causing dislocation and moves the humeral head toward the chest. Subsequently, sharp adduction leads to the fracture of the humeral head. Glessnern (32) and Patel et al. (15) proposed a similar mechanism in which a forced abduction dislocated the shoulder into the chest cavity, and the process of impact against the ribs would be when the fracture took place.

Similarly, Karr et al. (7) proposed a two-stage mechanism of injury. When the elbow was in the abduction position, the humeral head was fractured and dislocated, and the shoulder hit the ground causing the rib to fracture and the humeral head to be embedded in the chest cavity. As all these authors have concluded, a single traumatic force is unlikely to cause this type of injury (21). The injury mechanism of our case was associated with high-energy trauma of abduction and external rotation of the shoulder, and there was no need for a reduction operation. Spontaneous dislocation reduction occurred in most cases, and no reduction operation was needed.

This mechanism often leads to fracture-dislocation of four parts of the proximal end of the humerus. As an exception, two cases of two-part fracturedislocation were reported $(1,26)$; in addition, one case of three-part fracture-dislocation (31) and separation fracture of proximal humerus epiphysis (30) were reported in the literature. Humeral head fracturedislocation and chest penetration often occur due to high-energy injuries, mostly accompanied by related injuries. Pneumothorax, hemothorax, and other lung injuries almost always coexist. It is often associated with thoracic and limb injuries. Fractures of the scapula, humeral shaft, elbow, wrist, pelvis, and tibial plateau have also been reported. Vascular injuries, including aortic compression and subclavian artery, as well as costal neck trunk injuries, were also reported in the literature, followed by cases of rupture of the main bronchus (24). In addition to humeral head displacement to the ipsilateral thoracic cavity, there are other special cases, such as humeral head in the retroperitoneal space $(n=1)$ (33) and movement to 
the contralateral thoracic cavity $(n=2)(4,5)$.

When a nerve injury occurs, the axillary nerves generally tend to be involved, which is very difficult to evaluate in the initial physical examination. There have also been reports of the median nerve, ulnar nerve, and secondary brachial plexus trunk injuries. Most patients spontaneously recover without surgery although other patients do not fully recover $(3,4,6,9$, $27)$. In this paper, EMG showed normal axillary nerve.

Treatment of the humeral head differed from previous reports. There is no agreement on whether to remove the humeral head, most of which is removed to prevent potential complications. In early and subsequent individual cases, fragments of the humeral head remained in the chest $(1,7,10,15,27)$. Some scholars have suggested that it is necessary to remove fragments only when there are cardiopulmonary complications. The reason for the removal of bone fragments from the humeral head is that there may be related to complications, such as infection or foreign body reactions (18). It has been reported that the retained humeral head was removed six weeks later and was embedded in the pulmonary parenchyma with extensive adhesion requiring extensive resection (29). It is believed that fragments of the humeral head should be actively removed at an early stage. Although humeral head fragments are sterile, bone fragments may become a potential focus of infection complicating treatment. Extraction can be performed by thoracotomy or thoracoscopy. Ideally, minimally invasive methods, such as video-assisted thoracoscopy, should be adopted to remove the humeral head. After removing it, subsequent techniques for shoulder reconstruction will depend on the specific conditions of the patient.

Regarding the treatment of proximal humerus fracture, a surgeon must consider the risk of humeral head necrosis when determining the surgical plan, and the vitality of the humeral head determines the treatment of the proximal humerus. In three- or fourpart displaced fractures, there is a high risk of ischemic necrosis or nonunion of the head. Humeral head necrosis increased from approximately 25\% of three-part fractures to nearly $60 \%$ of four-part fractures $(9,34)$. In the orthopedic literature, there is still a great deal of controversy on which surgical option is the most appropriate. Open reduction and internal fixation are possible in younger patients (5, $22,26,30,31)$. In published articles, the majority of cases were treated with hemiarthroplasty of the glenohumeral joint $(2-6,8,9,11-13,18-21,23,27-$ 29), and one patient was treated with reverse shoulder arthroplasty (12).

Intrathoracic displacement of the humeral head due to proximal humeral fracture is a very rare and serious trauma that requires multidisciplinary treatment. Considering the extremely high risk of humeral head necrosis, actively removing the broken bone fragments of the humeral head in the early stage is recommended, and we advocate for shoulder arthroplasty for elderly patients. Detailed preoperative evaluations and individualized operation plans should be made to achieve the best effect.

Abbreviations: ROM: Range of Movement; ATLS: Advanced Trauma Life Support; DCS: Damage Control Surgery; CT: Computed Tomography; EMG: Electromyography

\section{Acknowledgments}

Not applicable.

\section{Footnotes}

Authors' Contribution: WC collected the data of the case and consulted relevant literature. YRF was a major contributor in writing the manuscript. All authors read and approved the final manuscript.

Conflicts of Interest: The authors have no conflict of interest to declare.

Ethical Approval: The experimental protocol was established according to the ethical guidelines of the Helsinki Declaration and was approved by the Human Ethics Committee of Lishui Central Hospital.

Funding/Support: Nil.

Financial Disclosure: None declared.

Informed consent: Written informed consent was obtained from the individual or guardian participants Availability of Data and Materials: All the data needed to achieve the conclusion are presented in the paper.

\section{References}

1. West EF. Intrathoracic dislocation of the humerus. J Bone Joint Surg Br. 1949;31B(1):61. [PubMed: 18112920].

2. Boyer P, Alsac JM, Ettori MA, Lesèche G, Huten D. Four-part fracture after intrathoracic displacement of the humeral head: a case report and review of the literature. Arch Orthop Trauma Surg. 2007;127(8):651-4. doi: 10.1007/s00402-007-0329-4. [PubMed: 17450370].

3. Wiesler ER, Smith AM, Shilt JS. Humeral head fracturedislocation into the thoracic outlet: case report and review of the literature. J Shoulder Elbow Surg. 2004;13(5):576-9. doi: 10.1016/j.jse.2004.02.011. [PubMed: 15383820].

4. Eberson CP, Ng T, Green A. Contralateral intrathoracic displacement of the humeral head. A case report. $J$ Bone Joint Surg Am. 2000;82(1):105-8. doi: 10.2106/00004623200001000-00013. [PubMed: 10653090].

5. Abbott GF, Gaissert H, Faberman RS. Contralateral intrathoracic migration of humeral head fracture dislocation. AJR Am J Roentgenol. 1999;172(5):1403-4. doi: 10.2214/ ajr.172.5.10227525. [PubMed: 10227525].

6. al-Kaar M, Garcia J, Khan HG, Manueddu C. Intrathoracic dislocation fracture of the head of the humerus. J Radiol. 1998;79(1):57-9. [PubMed: 9757223]

7. Kaar TK, Rice JJ, Mullan GB. Fracture-dislocation of the shoulder with intrathoracic displacement of the humeral head. Injury. 1995;26(9):638-9. doi: 10.1016/0020-1383(95)00120x. [PubMed: 8550176].

8. Jun-Song W, Jing-Yu D, Zhi-Qiang W, Fang G, Xiang-Jin L. Intrathoracic displacement of the humeral head in a trauma patient. Indian J Orthop. 2012;46(5):596-8. doi: 
10.4103/0019-5413.101050. [PubMed: 23162158].

9. Hawkes T, Parra M, Shrock K. Intrathoracic fracturedislocation of the proximal humerus treated with rib fixation and shoulder arthroplasty. Am J Orthop (Belle Mead NJ). 2014;43(4):E74-8. [PubMed: 24730008].

10. Du Plessis N, Rajendran S, Naqi SA, Cahill R. Intrathoracic fracture-dislocation of the humeral head. Is removal of the humeral head necessary? BMJ Case Rep. 2012;2012: bcr2012007478. doi: 10.1136/bcr-2012-007478. [PubMed: 23264271]

11. Daffner SD, Cipolle MD, Phillips TG. Fracture of the humeral neck with intrathoracic dislocation of the humeral head. I Emerg Med. 2010;38(4):439-43. doi: 10.1016/j.jemermed.2007.09.064. [PubMed: 18650050].

12. Maroney SS, Devinney DS. Intrathoracic fracture-dislocation of the proximal humerus treated with reverse total shoulder arthroplasty. Orthopedics. 2009;32(12):924. doi: 10.3928/01477447-20091020-21. [PubMed: 19968231].

13. Chen J, Yan J, Wang S, Zhong H, Zhou H. Intrathoracic dislocation of the humeral head accompanied by polytrauma: How to treat it? Ulus Travma Acil Cerrahi Derg. 2015;21(2):149-51. doi: 10.5505/tites.2015.72566. [PubMed: 25904278].

14. Schoffl H, Froschauer SM, Huemer GM. Intrathoracal displacement of the humeral head after fracture. Wien Klin Wochenschr. 2009;121(7-8):246. doi: 10.1007/s00508-0081096-0. [PubMed: 19562280].

15. Patel MR, Pardee ML, Singerman RC. Intrathoracic dislocation of the head of the humerus. J Bone Joint Surg Am. 1963;45:1712-4. [PubMed: 14083151].

16. Brogdon BG, Crotty JM, MacFeely L, McCann SB, Fitzgerald M. Intrathoracic fracture-dislocation of the humerus. Skeletal Radiol. 1995;24(5):383-5. doi: 10.1007/BF00197074. [PubMed: 7570162].

17. Rupprecht H, Ghidau M, Gaab K. Severe thoracic trauma due to an intrathoracic dislocation of a fractured humeral head in an aged patient; a case report. Bull Emerg Trauma. 2017; 5(3):212-4. [PubMed: 28795067].

18. Fernández AI, Fernández AG. Intrathoracic fracture-Dislocation of the shoulder. J Clin Orthop Trauma. 2018;9(Suppl 2):S54-7. doi: 10.1016/j.jcot.2018.04.001. [PubMed: 29928107].

19. Kocer B, Gulbahar G, Aktekin CN, Gunal N, Birinci B, Dural K, et al. Intrathoracic humeral head fracture-dislocation: is removal of the humeral head necessary? Ann Thorac Surg. 2007;84(4):1371-2. doi: 10.1016/j.athoracsur.2007.05.011. [PubMed: 17889001].

20. Harman BD, Miller NG, Probe RA. Intrathoracic humeral head fracture-dislocation. J Orthop Trauma. 2004;18(2):112-5. doi: 10.1097/00005131-200402000-00010. [PubMed: 14743032].

21. Liu HH, Lee YH, Yang SW, Wong CY. Fracture of the proximal humerus with intrathoracic dislocation of the humeral head. $J$ Trauma. 2007;63(2):E37-9. doi: 10.1097/01.ta.0000246958. 80088.5a. [PubMed: 17693816].

22. Anderson M, Rose P, Jacofsky DJ, Torchia ME, Dahm DL. Intrathoracic fracture-dislocation of the proximal humerus: a case report and report of a new surgical technique. J Trauma. 2007;63(4):920-3. doi: 10.1097/01.ta.0000224887.29787.a6. [PubMed: 17110887].

23. Tsai YM, Shen PH, Chang H, Tzao C, Lee SC, Cheng YL. Intrathoracic displacement of a fractured humeral head due to blunt trauma. Ann Thorac Cardiovasc Surg. 2014;20(Suppl): 592-4. doi: 10.5761/atcs.cr.12.02194. [PubMed: 23558222]

24. Hayes N, White J, Lillie P, Bennetts JS, Tu CG, Bain GI Intrathoracic shoulder dislocation causing rupture of the right main bronchus. Arch Orthop Trauma Surg. 2020;140(4):443-7. doi: 10.1007/s00402-019-03242-3. [PubMed: 31385020].

25. Sola Junior WC, Santos PS. Intrathoracic fracture-dislocation of the humerus - case report and literature review. Rev Bras Ortop. 2017;52(2):215-9. doi: 10.1016/j.rboe.2017.01.005. [PubMed: 28409141].

26. Simpson NS, Schwappach JR, Toby EB. Fracture-dislocation of the humerus with intrathoracic displacement of the humeral head. A case report. J Bone Joint Surg Am. 1998;80(6):889-91. doi: 10.2106/00004623-19980600000013. [PubMed: 9655107].

27. Abellan JF, Melendreras E, Gimenez DJ, Carrillo FJ, Ruano L, Rivkin J. Intrathoracic fracture-dislocation of the humeral head: a case report. J Orthop Surg (Hong Kong). 2010; 18(2):254-7. doi: 10.1177/230949901001800225. [PubMed: 20808024].

28. Salhiyyah K, Potter D, Sarkar PK. Fracture-dislocation of humeral head with intrathoracic displacement. Asian Cardiovasc Thorac Ann. 2012;20(2):196-8. doi: 10.1177/0218492311421450. [PubMed: 22499971].

29. Griffin NC, Temes RT, Gill IS, Rice TW. Intrathoracic displacement of a fractured humeral head. Ann Thorac Surg. 2007;84(4):1400. doi: 10.1016/j.athoracsur.2006.11.075. [PubMed: 17889016].

30. Guiotti Filho J, Borges AC, Leite MD. Epiphysiolysis fracture of the proximal end of the humerus with intrathoracic dislocation: case report. Braz J Orthop. 2008;43:48-52. doi: 10.1590/S0102-36162008000100007.

31. Hardcastle PH, Fisher TR. Intrathoracic displacement of the humeral head with fracture of the surgical neck. Injury. 1981;12(4):313-5. doi: 10.1016/0020-1383(81)90208-4. [PubMed: 7263035]

32. Glessner Jr JR. Intrathoracic dislocation of the humeral head JBJS. 1961;43(3):428-30.

33. Wirth MA, Jensen KL, Agarwal A, Curtis RJ, Rockwood CA Jr. Fracture-dislocation of the proximal part of the humerus with retroperitoneal displacement of the humeral head. A case report. J Bone Joint Surg Am. 1997;79(5):763-6. doi: 10.2106/00004623-199705000-00018. [PubMed: 9160951].

34. Besch L, Daniels-Wredenhagen M, Mueller M, Varoga D, Hilgert RE, Seekamp A. Hemiarthroplasty of the shoulder after fourpart fracture of the humeral head: a long-term analysis of 34 cases. J Trauma. 2009;66(1):211-4. doi: 10.1097/TA.0b013e31815d9649. [PubMed: 19131828]. 